\title{
Acute evaluation of static and dynamic stability of the lumbopelvic region after paravertebral stretching
}

\author{
Camila Amaral Coracini ${ }^{1, A-D, F \oplus}$, Pollyana Bortoletto ${ }^{1, A-C, E-F}{ }^{\oplus}$, Érica Provensi ${ }^{1, A-C, E-F \oplus}{ }^{\text {, }}$ \\ Mateus Vieira Furtuoso ${ }^{1, A-C, E-F}{ }^{\oplus}$, Gladson Ricardo Flor Bertolini ${ }^{1, A-C, E-F} \oplus$, \\ Alberito Rodrigo de Carvalho ${ }^{1, A-C, E-F}(\mathbb{0}$ \\ 1 Universidade Estadual do Oeste do Paraná, Brazil \\ A - Research concept and design, B - Collection and/or assembly of data, C - Data analysis and interpretation, \\ $D$ - Writing the article, $E$ - Critical revision of the article, $F$ - Final approval of article
} Coracini C. A, Bortoletto P, Provensi E, Furtuoso M.V, Flor Bertolini G. R, de Carvalho A. R. Acute evaluation of static and dynamic stability of
the lumbopelvic region after paravertebral stretching. J Pre-Clin Clin Res. 2019; 13(4): 150-152. doi: 10.26444/jpccr/113279

\begin{abstract}
Introduction and objectives. Since the paravertebral muscles promote dynamic stability to protect the spine, the aim of this study was to verify the association between the acute effect of the stretching support time for the multifidus muscle, and changes in the static and dynamic stability of the lumbopelvic region.

Materials and method. A total of 46 volunteers were cross-submitted to three different stretching interventions for the multifidus muscle, being the manutention of stretching time the variation between interventions: 10,30 and 60 seconds. Each volunteer was submitted to the three interventions with a minimum interval of 7 days and a maximum of 10 days. The order of the interventions was determined by lot. First, pre-intervention values for static and dynamic stability were collected using a biofeedback pressure unit. Subsequently, the sample was forwarded for intervention according to its group; after the completion of the same, data were collected on post-intervention stability. The data were analyzed using SPSS 20.0 software and Chi-square test, with a significance level of $5 \%(a=0.05)$.

Results. There was no significant association between the manutention of stretching time and static stability, being $\mathrm{X} 2(4)=0.812 ; \mathrm{p}=0.949$. Similarly, there was no significant association between the stretching support time and dynamic stability, and $\mathrm{X} 2(4)=1.517 ; \mathrm{p}=0.827$.

Conclusion. In conclusion, there was no significant association between stretching time of the paravertebral muscles and static and dynamic stability.
\end{abstract}

\section{Key words}

muscle stretching exercises, muscle relaxation, muscle strength

\section{INTRODUCTION}

Static stretching is defined as the act of stretching until a feeling of stretching is reached, and keeping the muscle in this position for a certain period of time. It is usually used in clinical and sport settings with the aim of increasing joint range of motion and reducing the risk of injuries [1].However, some studies have reported adverse effects of this type of stretching on muscle performance. Recent reviews have addressed a dose-response effect in which long stretching duration (more than 60 seconds) cause impairments in athletic and clinical performanc $[2,3]$. This happens because motor messages are slowly transmitted because of deformations of the plastic and elastic muscle components. Therefore, long stretching time allows the relaxation of muscle fibers, causing significant reduction in muscle tone and activation of the parasympathetic system [1].

As previously mentioned, the muscles have elastic components. These comprise of the tendons and part of the structure of the bridges that join the actin and myosin filaments [4]. When submitted to static stretching exercises,

Address for correspondence: Gladson Ricardo Flor Bertolini, Universidade Estadual do Oeste do Paraná, Rua Universitária, 2069., 85819110, Cascavel, Brazil E-mail: gladsonricardo@gmail.com

Received: 23.08.2019; accepted: 22.10.2019; first published: 31.12.2019 there is an increase in muscular complacency that can limit the coupling of the crossed bridge, decreasing the capacity of the muscle to produce strength. Thus, protection of other structures promoted by the muscle is diminished, generating, among others, a decrease in the dynamic stability of the spine, caused by the paravertebral muscles [5].

Among the paravertebral muscles, those relevant to this study are the multifidus, because they control the stabilization of the lumbar spine, and provide support and segmental control [6]. As a method for stretching and strengthening them, the Williams Series exercises can be used because, developed by Paul Williams, were aimed initially at promoting trunk stability in patients with chronic low back pain [5].

Based on this information, it is noted that there is evidence proving that static stretches maintained for 60 seconds or more are harmful to muscle performance; and that the Williams Series exercises promote stretching of the paravertebral muscles. However, there is no conclusive evidence associating the effects of static stretching on the stability of the lumbopelvic musculature, promoted by the multifidus.

Therefore, the research issue of this study seeks to verify how the static and dynamic stabilization of the deep lumbopelvic musculature is affected when submitted to an exercise of the Williams Series with different maintenance time of static stretching. 


\section{OBJECTIVE}

To verify the association between the acute effect of the stretching support time for the multifidus muscle and the changes in the static and dynamic stability of the lumbopelvic region.

\section{MATERIALS AND METHOD}

This crossed clinical trial study was approved by the Ethics Committee on Research Involving Human Beings of the Universidade Estadual do Oeste do Paraná - UNIOESTE (Protocol 2748177). All volunteers signed a free and informed consent form in two copies, one of which was retained by the volunteer and the other by the researcher.

The sample consisted of 46 volunteers of both genders, aged between 18 - 35 years, with no history of musculoskeletal lesion in the spine or lower limbs. All volunteers were crosssubmitted to three different stretching interventions for the multifidus muscle, being the manutention of stretching time with variation between interventions: 10,30 and 60 seconds. Each volunteer was submitted to the three interventions with a minimum interval of 7 days and a maximum of 10 days. The order of the interventions was determined by lot.

The inclusion criteria were: no history of spinal or lower limb disorders, either acute or chronic, in the last 12 months and no regular and systematic physical activity. No volunteers with a history of abdominal, hip and spine surgeries participated in the study, regardless of the time they were performed; pregnant women; those who use medications that promote muscle relaxation.

Collections took place in the Laboratory of Integrative Biodynamic Evaluation of the Human Movement of the Physiotherapy course of UNIOESTE. Initially, the volunteers were informed about the objectives and procedures of the research and were later invited to give their consent to participate in the study. Each volunteer participated in a battery of tests, clinical evaluation and familiarization, totaling four visits to the laboratory with a minimum of 7 days and a maximum of 10 days between visits.

During the first visit, a brief clinical evaluation was performed, consisting of personal data, history of injury and use of medications. The volunteer was then familiarized with the intervention procedure. The stretching proposed being the "Knees in the Breast" exercise, number three in the Williams Series. The participant was positioned in a supine position, with the knees flexed, the feet supported on the stretcher and the arms relaxed at the side of the trunk. On the therapist's command, the volunteer took the feet off the stretcher, lifted the knees towards the chest and held them with his hands for the time previously stipulated for each intervention. Only then, after the researcher's command, the legs were relaxed. In this familiarization, repetitions were performed with the help of the evaluator until the volunteer had learned the correct execution of the stretching.

Familiarization was also made with the movements of static and dynamic stability evaluation, which were evaluated by a MioStab (Miotec ${ }^{\oplus}$, Porto Alegre, Brazil) biofeedback pressure unit (BPU). Only after familiarization was the order of interventions for each volunteer drawn. In all tests, the subjects were placed in the dorsal decubitus position, with arms extended along the body, knees bent, and feet supported on the stretcher. The BPU bag was inflated to the pressure established for each test, and positioned horizontally and centrally in the region comprising the last ribs and the posterior superior iliac spine (PSIS). After positioning, the subject was asked to perform a forced respiratory cycle and, if necessary, pocket pressure was adjusted again. The execution of the tests followed the recommendations suggested in the equipment manual [7].

For the static stability evaluation, the pressure bag was inflated to a pressure of $40 \mathrm{mmHg}$ and the volunteer instructed to breathe normally and, upon exhaling, to contract the muscles of the posterior region of the trunk, trying to remove the contact of the back with the equipment. This compression should last at least 10 seconds. The classification of the change was: maintained, when there was no change in static stability before and after stretching; worsened, when the stability at the prestretching moment was better than at the post-stretching condition; improved, when the stability at the prestretching moment was worse than at the post-stretching condition.

To evaluate the dynamic stability, the pressure bag was inflated to a pressure of $40 \mathrm{mmHg}$ and the volunteer was instructed to breathe normally and, upon expiration, to abduct one of the lower limbs in order to touch the lateral face of the limb on the stretcher, keeping the foot support in the maximum possible range, returning to the initial position afterwards. Three attempts were requested, with an interval of two minutes between each one. In this test, the volunteer's ability to at least maintain the established initial pressure was evaluated. In the cases in which the subject could not maintain the minimum pressure of $40 \mathrm{mmHg}$ during the test, the dynamic stability was considered deficient.

During visits two to four, stability tests initially took place. Subsequently, the stretching exercise was applied, always following the same procedure, and variations occurred only with respect to sustaining the same time of 10,30 or 60 seconds. After the intervention, the stability was reassessed. In the case of the CG, the participants underwent both pre- and post-evaluations, but as an intervention they were instructed only to remain lying supine, with the lower limbs extended, as relaxed as possible, for 30 seconds.

SPSS 20.0 software was used for statistical analysis. The level of significance adopted was $5 \%(\alpha=0.05)$. The statistical test used was the Chi-square test with a $3 \times 3$ contingency table. The effect size was expressed by the relative risk, which was calculated according to a methodology previously described in the literature [8].

\section{RESULTS}

A total of 46 volunteers participated in the study with a mean age of $20.3 \pm 2.1$ years, height $1.65 \pm 0.07 \mathrm{~m}$ and body mass $67.2 \pm 11.9 \mathrm{~kg}$.

There was no significant association between the stretching support time and static stability $-\chi 2(4)=0.812 ; \mathrm{p}=0.949$. Similarly, there was no significant association between the stretching support time and dynamic stability, and $\chi 2(4)=1.517 ; p=0.827$. The $3 \times 3$ contingency tables of frequency distribution, both for the effects of the stretching support time on static and dynamic stability, are shown in Tables 1 and 2 , respectively.

The results described in Table 1 represent the fact that, based on the odds, when sustaining the stretching for 10 
Table 1. Distribution of frequencies (number of cases) obtained for each combination of categories between lengthening support time and effect on the static stability of the deep muscles of the lumbopelvic region

\begin{tabular}{lccccc}
\hline Variables & & \multicolumn{3}{c}{ Effect on Static Stability } & \multirow{2}{*}{ Total } \\
\cline { 2 - 5 } & & Maintained & Worse & Improved & \\
\hline Stretching & $10 \mathrm{~S}$ & 37 & 4 & 5 & 46 \\
\cline { 2 - 5 } Time & $30 \mathrm{~S}$ & 38 & 5 & 3 & 46 \\
\hline & $60 \mathrm{~S}$ & 36 & 5 & 5 & 46 \\
\hline Total & & $\mathbf{1 1 1}$ & $\mathbf{1 4}$ & $\mathbf{1 3}$ & 138 \\
\hline
\end{tabular}

Table 2. Distribution of frequencies (number of cases) obtained for each combination of categories between lengthening support time and effect on the dynamic stability of deep muscles in the lumbopelvic region

\begin{tabular}{lccccc}
\hline Variables & & \multicolumn{3}{c}{ Effect on Dinamic Stability } & \multirow{2}{*}{ Total } \\
\cline { 2 - 5 } & & Maintained & Worse & Improved & \\
\hline Stretching & $10 \mathrm{~s}$ & 34 & 5 & 7 & 46 \\
\cline { 2 - 5 } Time & $30 \mathrm{~s}$ & 34 & 7 & 5 & 46 \\
\hline \multirow{2}{*}{ Total } & $60 \mathrm{~s}$ & 37 & 4 & 5 & 46 \\
\hline
\end{tabular}

seconds it has 9.25 more chances of maintaining static stability than worsening it, and also have 7.4 more chances of maintaining than improving it. By sustaining the stretching for 30 seconds, it has 7.6 more chances of maintaining static stability than worsening it, and also have 12.6 more chances of maintaining than improving it. When sustaining the stretching for 60 seconds, one has 7.26 more chances to maintain the static stability than worsening or improving it.

The results described in Table 2 represent the fact that, based on the chances, when sustaining the stretching for 10 seconds, one has 6.8 more chances of maintaining dynamic stability than worsening it, and also 4.8 more chances of maintaining it than improving it. By sustaining the stretching for 30 seconds, one has 4.8 more chances of maintaining dynamic stability than worsening it, and also 6.8 more chances of maintaining than improving it. By sustaining the stretching for 60 seconds, one has 9.25 more chances of maintaining dynamic stability than worsening it, and also 7.4 more chances of maintaining than improving it.

\section{DISCUSSION}

The word "stabilization" can be defined as the action of the muscles on the limiters and controllers of movement, thus being able to act in the prevention of damage to ligaments and capsules; referring, therefore, to mechanical joint control [9]. One of the muscles responsible for this lumbopelvic stabilization is the multifidus, because its location is close to the centre of rotation of the lumbar joint. Thus, the superficial fibres are adapted to control the orientation of the spine, while the deep fibres control the intervertebral movement [10].

According to the literature, when a muscle is submitted to a static stretching sustained for long duration, there is the promotion of relaxation of muscle fibres, deformation of plastic and elastic components, and reduction of muscle strength performance. Thus, stretching can reduce the stability promoted by the muscle in question $[1,2,11]$.

It is known that the promotion of segmental stability is widely associated with the muscle strength of the stabilizing muscles. According to Goulart et al.[12], the greater muscle strength that the lumbar region has, the better the capacity to store elastic energy, creating better stability, avoiding possible disorders that would trigger pain.

In a study conducted by Paungmali et al.[13], 25 individuals with chronic low back pain underwent three experimental conditions: lumbopelvic stabilization training (using a biofeedback pressure unit); placebo (automated cycling); and control (rest). As a result, there was an improvement in stability after muscle strength training in the lumbopelvic regio, thus reaffirming that described previousl by Goulart et al. [12]y.

However, despite the fact that the literature states that stretching promotes a reduction in muscle strength, which is directly related to stabilization, in this study there was no significant association - positive or negative - between stretching and static and dynamic lumbopelvic stability.

\section{CONCLUSION}

There was no significant association between the stretching time of the multifidus muscle in the static and dynamic stability of the lumbopelvic region.

\section{Acknowledgments}

The authors express their thanks to the Araucária Foundation for the grant of a scientific initiation scholarship.

\section{REFERENCES}

1. McHugh MP, Cosgrave $\mathrm{CH}$. To stretch or not to stretch: the role of stretching in injury prevention and performance. Scand J Med Sci Sport. 2010;20(2):169-81.

2. Kay AD, Blazevich AJ. The effect of acute static stretch on maximal muscle performance: a systematic review. Med Sci Sport Exerc. 2012;44(1):154-64.

3. Behm DG, Blazevich AJ, Kay AD, Mchugh M. Acute effects of muscle stretching on physical performance, range of motion, and injury incidence in healthy active individuals: a systematic review. Appl Physiol Nutr Metab. 2016;41(1):1-11.

4. Freitas SR, Mendes B, Le Sant G, Andrade RJ, Nordez A, Milanovic Z. Can chronic stretching change the muscle-tendon mechanical properties? A review. Scand J Med Sci Sports. 2018;28(3):794-806.

5. Silva MAC, Dias JM, Silva MF, Mazuquin BF, Abrão T, Cardoso JR. Análise comparativa da atividade elétrica do músculo multífido durante exercícios do Pilates, série de Williams e Spine Stabilization. Fisioter em Mov. 2013 Mar;26(1):87-94.

6. Ward SR, Kim CW, Eng CM, Gottschalk LJ, Tomiya A, Garfin SR, et al. Architectural analysis and intraoperative measurements demonstrate the unique design of the multifidus muscle for lumbar spine stability. J Bone Joint Surg Am. 2009 Jan;91(1):176-85.

7. Schmit EFD, Pivotto LR, Ribeiro RP, Aimi MA, Vieira A, Candotti CT. Manual de utilização do MioStab: estabilizador de coluna. Grup Investig da Mecânica do Mov Esc Educ Fis Fisioter e Dança/UFRGS. 2015;1-14.

8. Field A. Descobrindo a estatística usando o SPSS. 2nd ed. Artmed, editor. Porto Alegre/RS; 2009. 688 p.

9. Melo Filho J, Menossi BR dos S, Preis C, Bertassoni Neto L, Stabelini Neto A. Análise da musculatura estabilizadora lombopélvica em jovens com e sem dor lombar. Fisioter em Mov. 2013 Sep;26(3):587-94.

10. Moseley GL, Hodges PW, Gandevia SC. Deep and superficial fibers of the lumbar multifidus muscle are differentially active during voluntary arm movements. Spine (Phila Pa 1976). 2002;27(2):29-36.

11. Behm DG, Blazevich AJ, Kay AD, McHugh M. Acute effects of muscle stretching on physical performance, range of motion, and injury incidence in healthy active individuals: a systematic review. Appl Physiol Nutr Metab. 2016 Jan;41(1):1-11.

12. Goulart IP, Teixeira LP, Lara S. Análise postural da coluna cervical e cintura escapular de crianças praticantes e não praticantes do método pilates. Fisioter e Pesqui. 2016 Mar;23(1):38-44.

13. Paungmali A, Henry LJ, Sitilertpisan P, Pirunsan U, Uthaikhup S. Improvements in tissue blood flow and lumbopelvic stability after lumbopelvic core stabilization training in patients with chronic nonspecific low back pain. J Phys Ther Sci. 2016;28(2):635-40. 